\title{
PENGARUH SENI DAN SOSIAL BUDAYA TERHADAP PERSEPSI MASYARAKAT MENGENAI TATO MENGGUNAKAN STRUCTURAL EQUATION MODELING (SEM)
}

\author{
I Gede Gandeva Umbara ${ }^{1 \S}$, Ni Luh Putu Suciptawati ${ }^{2}$, \\ Desak Putu Eka Nilakusmawati ${ }^{3}$
}

${ }^{1}$ Program studi Matematika, Fakultas MIPA - Universitas Udayana [Email: gandevaumbara@gmail.com]

${ }^{2}$ Program studi Matematika, Fakultas MIPA - Universitas Udayana [Email: suciptawati@unud.ac.id]

${ }^{3}$ Program studi Matematika, Fakultas MIPA - Universitas Udayana [Email: nilakusmawati@unud.ac.id]

${ }^{\S}$ Corresponding Author

\begin{abstract}
This study purposed to know the effect of art and socio-culture on the public perception of tattoos. The data used in this study is the primary data collected using a questionnaires distributed to 200 people with 100 non-tattooed people and 100 tattooed people. This study used covariance-based Structural Equation Modeling (SEM) with AMOS software, and used three latent variables such as art, socio-culture and tattoo perception. The results of this study show art and socio-culture have a significant effect on tattoo perception.
\end{abstract}

Keywords: Perception, Tattoo, SEM, AMOS

\section{PENDAhuluan}

Saat ini tato lebih dikenal sebagai karya seni. Hal ini disebabkan terdapat kegiatan mendisain atau menggambar pola di dalam menato. Desainnya pun sudah beragam, mulai dari katakata, simbol-simbol, hingga gambar-gambar. Berbagai perlombaan tentang tato, semakin memperkenalkan kepada masyarakat bahwa tato merupakan karya seni. Hal ini semakin menggeser anggapan masyarakat bahwa orang bertato adalah penjahat atau kriminal.

Tato atau rajah merupakan suatu tanda yang dibuat dengan memasukkan pigmen ke dalam kulit. Kata tato berarti menandakan sesuatu yang berasal dari bahasa Tahiti yaitu tatu. Tato juga didefinisikan sebagai gambar, lukisan, pada bagian atau anggota tubuh, yang memiliki arti sesuatu bagi pemiliknya (LeMay, 2008).

Terdapat dua jenis tato yaitu : (1) Tato permanen. Tato ini dibuat dengan menusukkan jarum dan memasukkan tinta kedalam kulit. Tato ini tidak berubah ubah; (2) Tato temporer atau body art. Tato ini dibuat tidak menggunakan jarum namun dengan tinta yang hanya ditempelkan diatas kulit. Tato ini tidak bisa tahan lama.

Seiring berjalannya waktu, seni membuat tato dapat digunakan sebagai ajang mencari nafkah bagi para seniman tato. Banyak seniman tato yang menawarkan jasa mereka pada studio studio tato. Salah satunya adalah di Kabupaten Badung. Pengguna jasa ini dari berbagai usia yang merupakan wisatawan asing, wisatawan domestik maupun warga lokal.

Banyak pandangan atau persepsi seseorang mengenai tato. Banyak pula hal yang mempengaruhi persepsinya. Persepsi merupakan proses kognitif yang mana digunakan oleh seseorang untuk dapat menafsirkan serta memahami dunia yang ada di sekitarnya terhadap sebuah objek (Gibson et al., 1989). Setiap orang memberikan definisi yang berbeda walaupun objeknya sama karena proses penafsirkan serta memahami sesuatu yang ada di sekitarnya dilakukan oleh individu.

Menurut Sobur (2003) terdapat tiga komponen utama dalam proses persepsi. (1) 
Seleksi, yaitu penyampaian rangsangan oleh indra yang intensitas maupun jenisnya baik banyak ataupun sedikit. Setelah diterima, rangsangan tersebut diseleksi; (2) Interpretasi, yaitu proses mengorganisasikan informasi oleh seseorang sehingga memiliki makna dan dapat dipengaruhi oleh berbagai hal. Interpretasi juga bergantung pada kemampuan seseorang untuk mengolah informasi yang kompleks menjadi sederhana; (3) Pembulatan, yaitu penarikan kesimpulan terhadap informasi yang diterima dan bereaksi baik dalam bentuk tingkah laku, pendapat/sikap dan lain sebagainya.

Penelitian mengenai persepsi tato pernah dilakukan oleh Anwar (2009). Hasilnya respon positif yang menyatakan tato merupakan seni dan akulturasi budaya. Respon negatif datang dari segi agama yang menyatakan tato identik dengan preman. Penelitian Wardhana (2014) memperoleh bahwa faktor yang berperan dalam mempersepsikan tato adalah agama, lingkungan sosial, budaya, dan pekerjaan. Tato juga mengalami pergeseran makna yang dulunya dianggap identik dengan kejahatan menjadi sebuah seni.

Selanjutnya Ankirskiy (2014) menyatakan bahwa dahulu tato merupakan hukuman dan identifikasi sosial namun sekarang sebagai seni yang patut dihargai. Rachman (2015) menyatakan banyak hal yang memotivasi orang untuk menato dirinya. Motivasi tersebut berasal dari internal dan eksternal. Motivasi internal misalnya minat, ekspresi, dan bentuk kekecewaan. Motivasi eksternal misalnya pengaruh teman sebaya, dukungan keluarga, dan idola.

Berdasarkan penelitian-penelitian kualitatif yang dilakukan oleh Anwar (2009), Wardhana (2014) dan Ankirskiy (2014) peneliti berasumsi faktor seni dan sosial budaya yang paling dominan mempengaruhi persepsi seseorang mengenai tato, maka peneliti tertarik untuk melakukan penelitian kuantitatif dengan meneliti pengaruh seni dan sosial budaya terhadap persepsi tato menggunakan structural equation modeling (SEM). Selanjutnya dari hasil yang didapakan diinterpretasikan untuk mengetahui pengaruh seni dan sosial budaya terhadap persepsi mengenai tato.

SEM merupakan bagian dari analisis multivariate. Analisis multivariat adalah metode pengolahan peubah (respon) yang jumlahnya lebih dari satu, dan tujuannya untuk mencari pengaruh peubah-peubah terhadap suatu obyek secara serentak. Analisis multivariat mengacu pada semua metode statistika yang menganalisis beberapa pengukuran pada setiap objek yang diamati secara simultan (Hair et al., 2010).

Secara umum analisis multivariat dapat dikelompokkan menjadi dua kelompok yaitu analisis dependensi dan analisis interdependensi. Analisis dependensi bertujuan untuk menjelaskan satu variabel terikat berdasarkan beberapa variabel bebas yang memengaruhinya sedangkan analisis interdependensi yang bertujuan untuk mengamati hubungan antar semua variabel yang ada.

Analisis SEM merupakan gabungan dari analisis faktor dan analisis regresi yang memungkinkan peneliti untuk menguji rangkaian hubungan yang saling terkait antara variabel terukur dengan variabel laten (Hair et al., 2010). SEM dapat digolongkan ke dalam analisis dependensi ketika berperan sebagai analisis regresi dan digolongkan ke dalam analisis interdependensi ketika berperan sebagai analisis faktor. SEM merupakan metode yang cukup populer dalam ilmu-ilmu sosial seperti politik, ekonomi, manajemen, sosiologi dan lainnya.

Terdapat dua jenis variabel dalam SEM, yaitu variabel laten dan variabel terukur. Variabel laten biasanya dilambangkan dengan elips dan terdiri dari variabel laten eksogen dilambangkan dengan $\xi$ (ksi) dan variabel laten endogen dilambangkan dengan $\eta$ (eta). Variabel terukur biasanya dilambangkan dengan $\square$ kotak dan terdiri dari variabel terukur yang menyatakan variabel laten eksogen dilambangkan dengan $\mathrm{X}$ dan variabel laten endogen dilambangkan dengan $\mathrm{Y}$. Hubungan antarvariabel dinyatakan melalui garis. Bentukbentuk hubungan antarvariabel ada dua, yaitu garis dengan anak panah satu arah dan garis dengan anak panah dua arah. 
Dalam SEM terdapat dua jenis model, yaitu model struktural dan model pengukuran. Model struktural merupakan sebuah model yang menghubungkan antar variabel laten sedangkan model pengukuran menggambarkan hubungan antar variabel laten dengan indikator-indikator teramati (Hair et al., 2010). Terdapat dua jenis indikator pengukuran, yaitu model indikator reflektif dan indikator formatif.

Dalam metode SEM estimasi yang paling umum digunakan adalah maximum likelihood estimation (MLE) (Mattjik \& Sumertajaya, 2011). Dalam MLE terdapat asumsi yang harus terpenuhi jumlah sampel besar, instrumen valid dan reliabel dan data berdistribusi normal baik secara univariat maupun multivariat.

\section{METODE PENELITIAN}

Lokasi pada penelitian ini adalah di Kabupaten Badung. Pertimbangan pemilihan lokasi penelitian tersebut karena Kabupaten Badung merupakan lokasi pariwisata terbesar di Bali dan terdapat banyak studio tato. Data yang digunakan adalah data primer dengan sumber data didapat dengan menyebar kuesioner menggunakan skala likert. Hasil kuesioner selanjutnya diuji kelayakannya menggunakan uji validitas dan reliabilitas.

Adapun hipotesis pada penelitian ini adalah:

(1) Pengaruh seni terhadap persepsi tato

$\mathrm{H}_{0}$ : seni tidak memengaruhi persepsi tato

$\mathrm{H}_{1}$ : seni memengaruhi persepsi tato

(2) Pengaruh sosial budaya terhadap persepsi tato

$\mathrm{H}_{0}$ : sosial budaya tidak memengaruhi persepsi tato

$\mathrm{H}_{1}$ : sosial budaya memengaruhi persepsi tato

(3) Hubungan korelasi antara seni dan sosial budaya

$\mathrm{H}_{0}$ : seni dan sosial budaya tidak saling berkorelasi

$\mathrm{H}_{1}$ : seni dan sosial budaya saling berkorelasi

Data dianalisis menggunakan metode SEM dengan software AMOS 22.0. Tahapan analisis data adalah :

(1) Pengembangan model teoretis.

Pengembangan model teoretis merupakan langkah awal di mana sebuah kasus akan diidentifikasi secara teoretis. Hubungan antarvariabel yang diteliti haruslah didukung oleh teori yang kuat;

(2) Pengembangan diagram jalur.

Peneliti selanjutnya melakukan perancangan diagram jalur untuk mengetahui hubungan antarvariabel yang ada berdasarkan identifikasi masalah pada penelitian. Pengembangan diagram jalur dibuat berdasarkan hipotesis pada penelitian;

(3) Konversi diagram jalur ke dalam persamaan matematis pada model struktural dan model pengukuran.

Pada model stuktural terdapat tiga variabel laten yang terdiri dari dua variabel laten eksogen yaitu seni (S) dan sosial budaya (SB) serta terdapat satu variabel laten endogen yaitu persepsi tato (PT):

$$
(P T)=\gamma_{11}(S)+\gamma_{12}(S B)+\zeta_{1}
$$

Misalkan variabel laten (PT) yang diukur dengan lima indikator $\mathrm{Y}_{1}, \mathrm{Y}_{2}, \mathrm{Y}_{3}, \ldots, \mathrm{Y}_{5}$ :

$$
\begin{aligned}
& Y_{1}=\lambda_{y 11} P T+\varepsilon_{1} \\
& Y_{2}=\lambda_{y 21} P T+\varepsilon_{2} \\
& Y_{3}=\lambda_{y 31} P T+\varepsilon_{3} \\
& Y_{4}=\lambda_{y 41} P T+\varepsilon_{4} \\
& Y_{5}=\lambda_{y 51} P T+\varepsilon_{5}
\end{aligned}
$$

(4) Pemilihan matriks input dan estimasi model. Peneliti dapat memilih matriks input data yang digunakan yaitu matriks varian/kovarian atau matriks korelasi. Pada penelitian ini estimasi model yang digunakan adalah maximum likelihood estimastion (MLE). Pada MLE data penelitian yang diperoleh memenuhi beberapa asumsi seperti validitas, berdistribusi normal, dan tidak terdapat pencilan. MLE kurang baik digunakan pada sampel dengan jumlah yang relatif kecil;

(5) Evaluasi Goodness of Fit.

Evaluasi goodness of fit bertujuan untuk mengevaluasi atau mengetahui kesesuaian model yang dihipotesiskan terhadap sampel data. Adapun beberapa goodness of fit yang digunakan adalah Chi-square, CMIN/DF, GFI, TLI, dan RMSEA;

(6) Interpretasi model.

Interpretasi model bertujuan untuk merangkum dan memberi informasi berdasarkan data yang 
telah diolah. Data yang telah diolah akan menunjukkan seberapa besar hubungan antarvariabel laten dan hubungan antara variabel

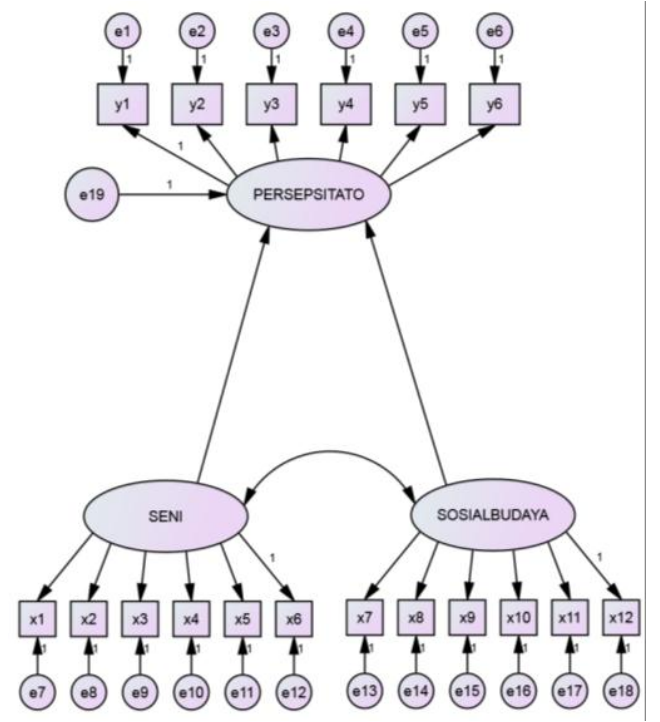

Gambar 1. Rancangan Model keseluruhan (Full Model)

\section{HASIL DAN PEMBAHASAN}

Dalam metode SEM estimasi yang umum digunakan adalah maximum likelihood estimation (MLE). Asumsi-asumsi pada MLE yang harus terpenuhi adalah jumlah sampel besar, instrumen valid dan reliabel dan data berdistribusi normal baik secara univariat maupun multivariat. Pada penelitian ini data yang digunakan sebanyak 200 buah. Jumlah tersebut sudah dapat dianggap memenuhi asumsi sampel besar yang diharuskan pada MLE.

Tabel 1. Nilai Cronbach Alpha dan Korelasi Item-Total Seni

\begin{tabular}{|c|l|c|}
\hline & \multicolumn{1}{|c|}{ Indikator } & $\begin{array}{c}\text { Corr } \\
\text { Item- } \\
\text { Total }\end{array}$ \\
\hline $\mathrm{X}_{1}$ & $\begin{array}{l}\text { Objek yang dapat dinikmati oleh } \\
\text { indra yang memiliki nilai seni tinggi }\end{array}$ & 0,698 \\
\hline $\mathrm{X}_{2}$ & Bentuk kreativitas dalam seni rupa & 0,563 \\
\hline $\mathrm{X}_{3}$ & $\begin{array}{l}\text { Seni body art yang selalu } \\
\text { mengalami perkembangan (inovasi) }\end{array}$ & 0,447 \\
\hline $\mathrm{X}_{4}$ & $\begin{array}{l}\text { Hasil ekspresi jiwa yang } \\
\text { menunjukkan perasaan penggunanya }\end{array}$ & 0,462 \\
\hline $\mathrm{X}_{5}$ & $\begin{array}{l}\text { Memperindah penampilan } \\
\text { penggunanya }\end{array}$ & 0,692 \\
\hline $\mathrm{X}_{6}$ & $\begin{array}{l}\text { Salah satu penyaluran minat dan } \\
\text { bakat dari pengguna dan seniman } \\
\text { tato }\end{array}$ & 0,697 \\
\hline \multicolumn{3}{|c|}{ Cronbach's Alpha 0,825 } \\
\hline
\end{tabular}

laten dan variabel terukur. Hasil analisis akan memberikan sebuah jawaban atau kesimpulan dari hipotesis yang telah dibuat.

Sebelum dipergunakan dalam pengumpulan data terlebih dahulu instrumen kuisioner tersebut diuji kelayakannya menggunakan uji validitas dan reliabilitas. Instrumen dikatakan valid apabila nilai koefisien korelasi antara item pernyataan dengan skor total $\geq 0,30$. Jika nilai Cronbach Alpha $\geq 0,60$ maka instrumen dikatakan reliabel (Hair et al., 2010).

Berdasarkan Tabel 1 seluruh instrumen dikatakan valid karena nilai dari koefisien korelasi item total (corr item-total) untuk setiap instrumen $\geq 0,3$. Cronbach's Alpha variabel seni menunjukkan nilai $0,825 \geq 0,60$ yang berarti reliabel.

Tabel 2. Nilai Cronbach Alpha dan Korelasi Item-Total Sosial Budaya

\begin{tabular}{|c|l|c|}
\hline \multicolumn{1}{|c|}{ Indikator } & $\begin{array}{c}\text { Corr } \\
\text { Item- } \\
\text { Total }\end{array}$ \\
\hline $\mathrm{X}_{7}$ & Sebuah gaya hidup & 0,760 \\
\hline $\mathrm{X}_{8}$ & $\begin{array}{l}\text { Sesuatu yang mendapat diskriminasi } \\
\text { (perlakuan berbeda) }\end{array}$ & 0,674 \\
\hline $\mathrm{X}_{9}$ & Identik dengan criminal & 0,778 \\
\hline $\mathrm{X}_{10}$ & $\begin{array}{l}\text { Bentuk identitas (individu maupun } \\
\text { kelompok) }\end{array}$ & 0,694 \\
\hline $\mathrm{X}_{11}$ & $\begin{array}{l}\text { Alat komunikasi non verbal } \\
\text { (komunikasi tak langsung) }\end{array}$ & 0,686 \\
\hline $\mathrm{X}_{12}$ & $\begin{array}{l}\text { Dipercaya mendatangkan } \\
\text { kebaikan/keberuntungan }\end{array}$ & 0,622 \\
\hline \multicolumn{2}{|c|}{ Cronbach's Alpha 0,879 } \\
\hline
\end{tabular}

Berdasarkan Tabel 2 seluruh instrumen dikatakan valid karena nilai dari koefisien korelasi item total (corr item-total) untuk setiap instrumen $\geq 0,3$. Cronbach's Alpha variabel sosial budaya menunjukkan nilai $0,879 \geq 0,60$ yang berarti reliabel.

Tabel 3. Nilai Cronbach Alpha dan Korelasi Item-Total Persepsi Tato

\begin{tabular}{|c|l|c|}
\hline & \multicolumn{1}{|c|}{ Indikator } & $\begin{array}{c}\text { Corr } \\
\text { Item- } \\
\text { Total }\end{array}$ \\
\hline $\mathrm{Y}_{1}$ & $\begin{array}{l}\text { Industri kreatif yang menjadi sumber } \\
\text { mata pencaharian }\end{array}$ & 0,554 \\
\hline $\mathrm{Y}_{2}$ & Tidak membahayakan kesehatan & 0,604 \\
\hline $\mathrm{Y}_{3}$ & $\begin{array}{l}\text { Salah satu bentuk modifikasi tubuh } \\
\text { yang mengubah warna kulit }\end{array}$ & 0,516 \\
\hline $\mathrm{Y}_{4}$ & Menambah kepercayaan diri & 0,763 \\
\hline $\mathrm{Y}_{5}$ & $\begin{array}{l}\text { Bentuk kecintaan pada sesuatu } \\
\text { (benda, orang dan lain sebagainya) }\end{array}$ & 0,823 \\
\hline $\mathrm{Y}_{6}$ & Salah satu warisan kebudayaan & 0,805 \\
\hline \multicolumn{3}{|c|}{ Cronbach's Alpha 0,867} \\
\hline
\end{tabular}


Berdasarkan Tabel 3 seluruh instrumen dikatakan valid karena nilai dari koefisien korelasi item total (corr item-total) untuk setiap instrumen $\geq 0,3$. Cronbach's Alpha variabel persepsi tato menunjukkan nilai $0,805 \geq 0,60$ yang berarti reliabel.

Untuk menguji kenormalan baik secara univariat maupun multivariat, penelitian ini menggunakan software AMOS 22.0 dengan memperhatiakan nilai critical ratio (CR) yang dibandingkan dengan Z-tabel. Dengan taraf nyata sebesar 5\%, data dikatakan menyebar normal apabila nilai $\mathrm{CR} \leq \pm 1,96$. Hasil pada uji kenormalan tersebut menunjukkan data menyebar normal dengan beberapa instrumen/ indikator dihilangkan.

\subsection{Profil Responden}

Profil responden dalam penelitian ini disajikan pada Tabel 4.

Tabel 4. Profil Responden

\begin{tabular}{|c|c|c|c|c|c|}
\hline \multirow{2}{*}{$\begin{array}{c}\text { Varia- } \\
\text { bel }\end{array}$} & \multirow{2}{*}{ Kategori } & \multicolumn{2}{|c|}{ Jumlah } & \multicolumn{2}{|c|}{ Persentase (\%) } \\
\hline & & $\begin{array}{l}\text { Ber- } \\
\text { tato }\end{array}$ & Tidak & $\begin{array}{l}\text { Ber- } \\
\text { tato }\end{array}$ & Tidak \\
\hline \multirow[b]{2}{*}{$\begin{array}{c}\text { Jenis } \\
\text { Kelamin }\end{array}$} & Laki-laki & 100 & 66 & 50 & 33 \\
\hline & $\begin{array}{l}\text { Perempua } \\
\mathrm{n}\end{array}$ & 0 & 34 & 0 & 17 \\
\hline \multirow{6}{*}{$\begin{array}{l}\text { Pendidik } \\
\text { an } \\
\text { Terakhir }\end{array}$} & SD & 1 & 6 & 0,5 & 3 \\
\hline & SMP & 15 & 15 & 7,5 & 7,7 \\
\hline & $\begin{array}{l}\text { SMA/SM } \\
\text { K }\end{array}$ & 70 & 61 & 35 & 30,5 \\
\hline & $\begin{array}{l}\text { Diploma/ } \\
\text { Sarjana }\end{array}$ & 14 & 16 & 7 & 8 \\
\hline & $\begin{array}{l}\text { Pasca } \\
\text { sarjana }\end{array}$ & 0 & 2 & 0 & 1 \\
\hline & $\begin{array}{l}\text { Tidak } \\
\text { Sekolah }\end{array}$ & 0 & 0 & 0 & 0 \\
\hline \multirow{6}{*}{$\begin{array}{l}\text { Pekerja- } \\
\text { an }\end{array}$} & Pelajar & 1 & 26 & 0,5 & 13 \\
\hline & $\begin{array}{l}\text { PNS/ } \\
\text { BUMN }\end{array}$ & 0 & 5 & 0 & 2,5 \\
\hline & $\begin{array}{l}\text { POLRI/ } \\
\text { TNI }\end{array}$ & 0 & 2 & 0 & 1 \\
\hline & $\begin{array}{l}\text { Karyawan } \\
\text { Swasta/ } \\
\text { Wiraswas } \\
\text { ta }\end{array}$ & 51 & 52 & 25,5 & 26 \\
\hline & $\begin{array}{l}\text { Petani/ } \\
\text { Nelayan }\end{array}$ & 1 & 1 & 0,5 & 0,5 \\
\hline & Lainnya & 47 & 14 & 23,5 & 7 \\
\hline \multicolumn{2}{|c|}{ Modus Umur } & \multicolumn{2}{|c|}{ Bertato 45} & \multicolumn{2}{|c|}{ Tidak 22} \\
\hline
\end{tabular}

Berdasarkan Tabel 4 responden dominan berjenis kelamin laki-laki dan modus umur responden bertato 45 tahun dan responden tidak bertato 22 tahun. Terkait pendidikan terakhir, sebagian besar responden merupakan tamatan SMA/SMK diikuti dengan SMP dan Diploma/Sarjana. Berdasarkan jenis pekerjaannya untuk responden bertato, karyawan swasta/wiraswasta merupakan pekerjaan yang mendominasi diikuti oleh pekerjaan lainnya. Hal ini dikarenakan tidak ada larangan untuk mempunyai tato bagi pekerja yang bekerja pada sektor tersebut. Untuk responden tidak bertato karyawan swasta/wiraswasta merupakan pekerjaan yang mendominasi diikuti oleh pelajar. Hal ini dikarenakan pada pelajar ada larangan untuk tidak memiliki tato. Berikut merupakan model keseluruhan dari penelitian ini.

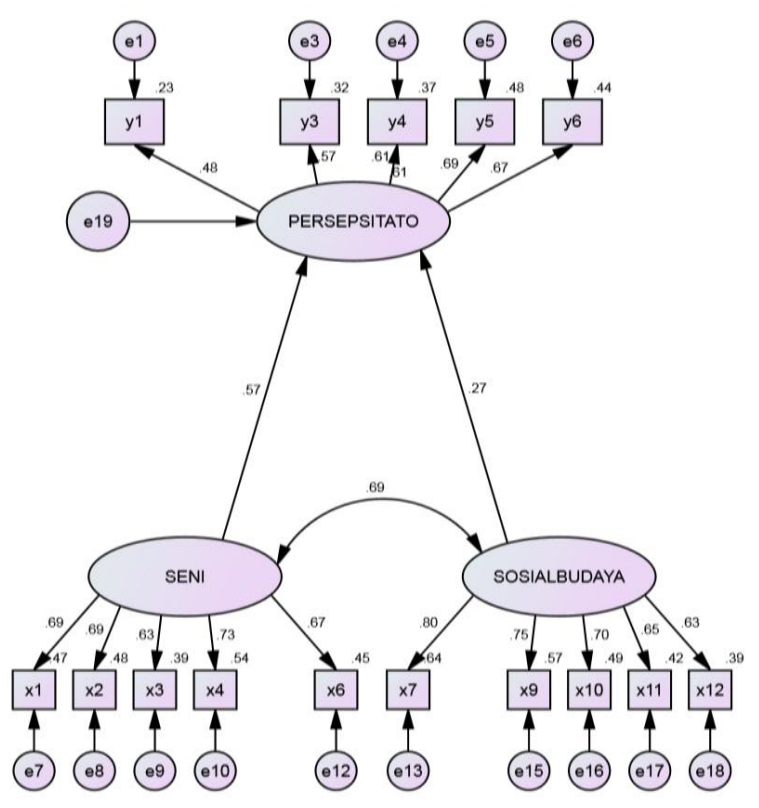

Gambar 2. Output Model Keseluruhan (Full Model)

Nilai-nilai yang ada pada gambar biasa disebut loading factor. Nilai tersebut dijelaskan pada model pengukuran dan model struktural.

\subsection{Model Pengukuran}

Hasil analisis terhadap model pengukuran memperlihatkan ada atau tidaknya pengaruh antara variabel laten dengan indikator. Hal ini dapat dilihat melalui nilai p-value yang dibandingkan dengan alpha (5\%). Jika p-value $\leq$ alpha maka dapat dikatakan signifikan. 
Tabel 5. Nilai Variabel Terukur Terhadap Variabel Laten

\begin{tabular}{|l|c|}
\hline \multicolumn{1}{|c|}{ Hubungan Kausal } & P-value \\
\hline Y1 $\leftarrow$ Persepsi Tato & \\
\hline Y3 $\leftarrow$ Persepsi Tato & $* * *$ \\
\hline Y4 $\leftarrow$ Persepsi Tato & $* * *$ \\
\hline Y5 $\leftarrow$ Persepsi Tato & $* * *$ \\
\hline Y6 $\leftarrow$ Persepsi Tato & \\
\hline $\mathrm{X} 12 \leftarrow$ Sosial Budaya & $* * *$ \\
\hline $\mathrm{X} 11 \leftarrow$ Sosial Budaya & $* * *$ \\
\hline $\mathrm{X} 10 \leftarrow$ Sosial Budaya & $* * *$ \\
\hline $\mathrm{X} 9 \leftarrow$ Sosial Budaya & $* * *$ \\
\hline $\mathrm{X} 7 \leftarrow$ Sosial Budaya & \\
\hline $\mathrm{X} 6 \leftarrow$ Seni & $* * *$ \\
\hline $\mathrm{X} 4 \leftarrow$ Seni & $* * *$ \\
\hline $\mathrm{X} 3 \leftarrow$ Seni & $* * *$ \\
\hline $\mathrm{X} 2 \leftarrow$ Seni & $* * *$ \\
\hline $\mathrm{X} 1 \leftarrow$ Seni & \\
\hline
\end{tabular}

Berdasarkan Tabel 5 ke 15 indikator dapat mewakili ketiga variabel laten. Seluruh nilai $p$ value sangat kecil $(* * *)$ atau kurang dari 0,05 yang berarti signifikan.

Besarnya pengaruh hubungan antara variabel laten dengan indikator dapat dilihat dari Tabel 6.

Tabel 6. Besar Nilai Variabel Terukur Terhadap Variabel Laten

\begin{tabular}{|l|c|}
\hline \multicolumn{1}{|c|}{ Hubungan } & Estimate \\
\hline Y1 $\leftarrow$ Persepsi Tato & 0,475 \\
\hline Y3 $\leftarrow$ Persepsi Tato & 0,566 \\
\hline Y4 $\leftarrow$ Persepsi Tato & 0,610 \\
\hline Y5 $\leftarrow$ Persepsi Tato & 0,691 \\
\hline Y6 $\leftarrow$ Persepsi Tato & 0,666 \\
\hline X12 $\leftarrow$ Sosial Budaya & 0,625 \\
\hline X11 $\leftarrow$ Sosial Budaya & 0,650 \\
\hline X10 Sosial Budaya & 0,701 \\
\hline X9 $\leftarrow$ Sosial Budaya & 0,753 \\
\hline X7 $\leftarrow$ Sosial Budaya & 0,797 \\
\hline X6 $\leftarrow$ Seni & 0,670 \\
\hline X4 $\leftarrow$ Seni & 0,734 \\
\hline X3 Seni & 0,627 \\
\hline X2 $\leftarrow$ Seni & 0,691 \\
\hline X1 $\leftarrow$ Seni & 0,685 \\
\hline
\end{tabular}

Bila ada nilai estimate yang bernilai > 1 maka akan menghasilkan nilai varians negatif (Murhadi, 2011). Berdasarkan Tabel 6 tidak ada nilai penduga yang lebih dari satu, sehingga untuk hasilnya dapat diintepretasikan dengan baik. X4 adalah indikator dengan nilai dugaan tertinggi untuk variabel seni. Hal ini sesuai dengan hasil yang didapatkan oleh Rezki (2016) yang menyatakan tato merupakan ekspresi perasaan terhadap sesuatu. X7 adalah indikator dengan nilai dugaan tertinggi untuk variabel sosial budaya. Hal ini sesuai dengan hasil yang didapatkan oleh Sukendar (2015) yang menyatakan tato merupakan bagian dari budaya lampau yang mengalami perubahan menjadi budaya pop. Y5 adalah indikator dengan nilai dugaan tertinggi untuk variabel persepsi tato. Hal ini sesuai dengan hasil yang didapatkan oleh Rezki (2016) menyatakan tato merupakan simbol makna ekspresi perasaan terhadap sesuatu hal yang penting didalam hidup.

\subsection{Model Struktural}

Hasil analisis terhadap model struktural memperlihatkan ada atau tidaknya pengaruh antarvariabel laten. Hal ini dapat dilihat melalui nilai p-value yang dibandingkan dengan alpha $(5 \%)$. Jika $p$-value $\leq$ alfa maka dapat dikatakan signifikan.

Tabel 7. Hubungan Antarvariabel Laten

\begin{tabular}{|l|c|}
\hline \multicolumn{1}{|c|}{ Hubungan } & P-value \\
\hline Persepsi Tato $\leftarrow$ Seni & $* * *$ \\
\hline Persepsi Tato $\leftarrow$ Sosial Budaya & 0,029 \\
\hline
\end{tabular}

Berdasarkan Tabel 7 variabel seni dan sosial budaya memiliki pengaruh yang signifikan terhadap persepsi tato karena memiliki nilai $p$ value $\leq 0,05$ atau sangat kecil $(* * *)$.

Besarnya pengaruh hubungan antara variabel laten eksogen dengan endogen dapat dilihat dari tabel 8 .

Tabel 8. Besar Hubungan Antarvariabel Laten

\begin{tabular}{|l|c|}
\hline \multicolumn{1}{|c|}{ Hubungan } & Estimate \\
\hline Persepsi Tato $\leftarrow$ Seni & 0,527 \\
\hline Persepsi Tato $\leftarrow$ Sosial Budaya & 0,268 \\
\hline
\end{tabular}

Bila ada nilai estimate yang bernilai > 1 maka akan menghasilkan nilai varians negatif (Murhadi, 2011). Berdasarkan Tabel 8 variabel sosial budaya mempunyai pengaruh yang lemah terhadap persepsi tato dengan nilai estimate yang dihasilkan sebesar 0,268. Variabel seni 
mempunyai pengaruh yang moderat terhadap perspsi tato dengan nilai estimate sebesar 0,572. Hal ini sesuai dengan hasil yang didapatkan oleh Ankirskiy (2014) yang menyatakan dahulu tato merupakan hukuman dan identifikasi sosial, namun sekarang sebagai seni yang patut dihargai.

Suatu variabel dinyatakan mempunyai korelasi apabila nilai $p$-value $\leq 0,05$. Hasil yang diperoleh nilai $p$-value $\leq 0,05$ atau sangat kecil (***). Jadi dapat dikatakan variabel seni dan sosial budaya saling berkorelasi. Besarnya nilai korelasi antarvariabel eksogen yaitu antara variabel seni dan sosial budaya mempunyai korelasi yang cukup tinggi sebesar 0,692. Setiap karya seni sedikit banyaknya mencerminkan setting masyarakat tempat seni itu diciptakan (Sumardjo, 2000). Jadi dapat dikatakan karya seni diciptakan seniman yang berasal dari kehidupan masyarakat.

Kesimpulan hipotesis pada penelitian ini adalah:

(1) Pengaruh seni terhadap persepsi tato

Tabel 7 menunjukan hubungan antara seni terhadap persepsi tato memiliki nilai $p$-value sangat kecil $(* * *)$. Dengan kata lain hubungan antara kedua variabel tersebut signifikan pada taraf nyata $5 \%$ sehingga tolak $\mathrm{H}_{0}$. Jadi seni berpengaruh terhadap persepsi tato.

(2) Pengaruh sosial budaya terhadap persepsi tato

Tabel 7 menunjukan hubungan antara sosial budaya terhadap persepsi tato memiliki nilai $p$ value 0,029. Dengan kata lain hubungan antara kedua variabel tersebut signifikan pada taraf nyata $5 \%$ sehingga tolak $\mathrm{H}_{0}$. Jadi sosial budaya berpengaruh terhadap persepsi tato.

\section{(3) Korelasi antara seni dan sosial}

Korelasi antara seni dan sosial budaya memiliki nilai $\mathrm{p}$-value 0,003 . Dengan kata lain hubungan antara kedua variabel tersebut signifikan pada taraf nyata 5\% sehingga tolak $\mathrm{H}_{0}$. Jadi terdapat korelasi yang nyata antara seni dan sosial budaya.

\section{SIMPULAN DAN SARAN}

\section{Simpulan}

Hasil penelitian dengan metode structural equation modeling terkait persepsi masyarakat mengenai tato, dapat disimpulkan bahwa seni dan sosial budaya mempunyai pengaruh yang signifikan terhadap persepsi tato. Pengaruh dari aspek seni moderat sedangkan pengaruh dari sosial budaya lemah terhadap persepsi tato.

\section{Saran}

Penelitian selanjutnya perlu dibedakan persepsi mengenai tato berdasarkan jenis kelamin pengguna tato. Bentuk tato juga dapat diamati yang terdiri dari tato kecil maupun besar untuk menyempurnakan dari penelitian mengenai tato sebelumnya.

\section{DAFTAR PUSTAKA}

Ankirskiy, A. (2014). Perception of Tattoos: Now and Then. Retrieved January 8, 2018, from skemman.is: https://skemman.is/bitstream/1946/17199/1/ perception-of-tattoos-now-and-then.pdf

Anwar, R. (2009). Persepsi Mahasiswa Terhadap Fenomena Tato. Skripsi. Medan: Universitas Sumatera Utara.

Gibson, J. L., Ivancevich, J. M., \& Konopaske, R. (1989). Organizations : Behavior Structure Processes. New York: McGraw Hill.

Hair, J. F., Black, W. C., Babin, B. j., \& Anderson, R. E. (2010). Multivariate Data Analysis (7'th ed.). New Jersey: Pearson Prentice Hall.

LeMay, R. (2008). The Body Modification Black Book : A Guide for Students, [Online]. Tersedia: http://www.ink-trails.com.

Mattjik, A., \& Sumertajaya, I. (2011). Sidik Peubah Ganda Dengan Menggunakan SAS (pertama ed.). Bogor: IPB PRESS.

Murhadi, W. (2011). Pemodelan SEM. Retrieved July 7, 2017, from hubla.dephub.go.id: http://hubla.dephub.go.id/publikasi/Laporan/ pemodelan-sem.pdf

Rachman, A. (2015). Motivasi Bertato Pada Remaja. Dipetik January 3, 2018, dari eprints.ums.ac.id: http://eprints.ums.ac.id/36597/

Rezki, R. (2016). Makna Tato Bagi Anggota Komunitas Tato di Tanjung Pinang. 
Retrieved July 9, 2018, from jurnal.umrah.ac.id:

http://jurnal.umrah.ac.id/wpcontent/uploads/gravity_forms/1ec61c9cb232a03a96d0947c6478e525e/2017 /01/JURNAL.pdf

Sobur, A. (2003). Psikologi Umum. Bandung: Pustaka Setia.

Sukendar, M. U. (2015). Tato dan Media Sosial. Jurnal Sainstech Politeknik Indonusa Surakarta Vol. 2 Nomor 4, 85-94.

Sumardjo, J. (2000). Filsafat Seni. Bandung: ITB.
Wardhana, T. H. (2014). Persepsi Mahasiswa Tidak Bertato Terhadap Fenomena Tato di Kalangan Mahasiswa Universitas

Brawijaya. Retrieved January 25, 2018, from www.academia.edu: http://www.academia.edu/8667437/PERSEP SI_MAHASISWA_TIDAK_BERTATO_TE RHADAP_FENOMENA_TATO_DI_KAL ANGAN_MAHASISWA_UNIVERSITAS_ BRAWIJAYA 